Revista Iberoamericana, Vol. LXXVII, Núms. 236-237, Julio-Diciembre 2011, 1051-1060

\title{
CAGLIOSTRO: UNA NOVELA-FILM DE VICENTE HUIDOBRO
}

\author{
POR \\ Andrea Ostrov \\ Universidad de Buenos Aires
}

La invención del cine -entre otros avances tecnológicos- determinante de la conformación del imaginario de la modernidad, constituye una innovación técnica que modifica radicalmente no sólo las posibilidades de representación sino la representación misma. Cuando Huidobro escribe su Cagliostro, en la década del 20, el cine mudo estaba en su apogeo y sus convenciones estéticas y procedimientos técnicos ya habían sido asimilados por el público e incorporados al gusto y a la sensibilidad de la época. Con esta obra, el autor se propone escribir una novela-film, incorporando a la escritura los procedimientos del nuevo arte. De hecho, su texto fue merecedor de un premio de US\$ 10.000 otorgado en 1927 por la League for Better Motion Pictures al libro con mayores posibilidades de ser filmado. Sin embargo, el estreno de la primera película sonora, The Jazz Singer, tan sólo un par de años después, aseguró el triunfo del cine hablado y contribuyó seguramente al "fracaso" del proyecto huidobriano. De acuerdo con René de Costa, "el Cagliostro de Huidobro, concebido según el sistema expresivo del cine mudo, quedó atrás, convertido en instantánea reliquia del pasado” (de Costa 67). Según este autor, existiría una versión fílmica de la novela realizada por el director rumano Mime Mizu, jamás estrenada y de la cual no se conserva ninguna copia. ${ }^{1}$ La novela se publica primero en inglés, en 1931, bajo el título The Mirror of a Mage y en castellano recién en 1934 con escaso éxito, a pesar de la apuesta del autor a que "el público [...] con la experiencia que tiene del cinematógrafo, puede comprender sin gran dificultad una novela de este género" (Huidobro 187). ${ }^{2}$

1 Para el año 1927 ya se habían filmado al menos cuatro películas sobre el personaje de Cagliostro: Le Miroir de Cagliostro (1899) de Georges Méliès; Cagliostro, Aventurier, chimiste et magicien (1910) de Camille de Morlhon; Der Graf von Cagliostro (1920) de Reinhold Schünzel y Cagliostro (1929) de Richard Oswald.

2 Cito aquí de sus Obras completas en la edición preparada y revisada por Hugo Montes (Vol. 2). René de Costa llama la atención sobre la dispar recepción que obtuvo la novela en sus dos versiones. Mientras los principales diarios en lengua inglesa encomiaron la obra, publicada en Londres y en Nueva York por importantes casas editoriales, la versión castellana, publicada en Chile en una edición popular, fue prácticamente ignorada. De Costa formula la hipótesis de que esta diferencia radicaría en el hecho 
Ahora bien, el acercamiento de Huidobro al cine va más allá de la mera fascinación por lo nuevo e incluso de la voluntad experimental, si tenemos en cuenta que la imagen es precisamente el principio constructivo de la estética creacionista. El poeta -según lo enuncia en sus múltiples manifiestos y textos sobre la creación- debe dejar de imitar a la naturaleza y crear, en cambio, objetos nuevos por medio de la imagen creacionista. Ésta se estructura a partir de la yuxtaposición de elementos normalmente disímiles o alejados entre sí en el mundo conocido, de manera tal que esa proximidad insólita generará nuevas articulaciones, nuevas vinculaciones que conformarán, en definitiva, un nuevo imaginario. Es decir que la estética huidobriana surge desde un primer momento estrechamente vinculada al campo de la visión. Si la transposición, la integración de las distintas artes, junto con el cuestionamiento de los límites genéricos que formaba parte de las búsquedas vanguardistas, ${ }^{3}$ Huidobro emprende muy tempranamente una búsqueda de proximidad entre el lenguaje literario y las artes visuales al escribir sus primeros poemas en forma de caligramas, que expone en París en 1922, como si se tratara de verdaderos cuadros.

La coherencia impecable que Huidobro establece entre sus postulados teóricos y su escritura poética permite reconocer en cada una de sus producciones la concreción cabal de su proyecto literario, dentro del cual la novela Cagliostro ${ }^{4}$ constituye sin duda uno de los momentos culminantes: "He querido escribir sobre Cagliostro una novela visual. En ella la técnica, los medios de expresión, los acontecimientos elegidos, concurren hacia una forma realmente cinematográfica” (187).

de que "[l]a versión inglesa llevaba un prolijo prefacio sobre el principio informador de la obra, una atinada exposición de su calidad fílmica. Parte de este prefacio -suprimido en la versión castellana- es fundamental para el entendimiento cabal de la tentativa de Huidobro" (70).

3 Según Fernando Burgos "la totalidad de las manifestaciones literarias de la vanguardia traspasaron los límites de su especificidad hacia otras artes y también hacia esferas que tradicionalmente no se reconocían como artísticas” (165).

4 La elección del personaje histórico Giuseppe Balsamo, conde Alessandro Cagliostro, médico y alquimista italiano efectivamente vinculado a la Logia de los Rosacruces, que frecuenta la corte de Francia durante los años previos a la Revolución, resulta significativa al menos en dos aspectos. Por un lado, Huidobro ya había establecido comparaciones entre poesía y magia: “aquí yace Vicente antipoeta y mago" (Altazor, Canto IV, verso 287). La figura del protagonista entonces puede vincularse fácilmente a la del poeta, su magia a la concepción creacionista de la escritura, y su laboratorio a la "cocina” del escritor: "la magia del personaje Cagliostro resultaba indistinguible del efecto ilusorio que Huidobro se proponía con su novelafilm. [...] Su alquimia era la alquimia del texto que se transformaba” (Burgos 168). En este sentido, no es casual la proliferación de distintos tipos de texto que atraviesan la novela: documentos secretos, cartas, esquelas, mensajes, actas de fundación, todos los cuales son sistemáticamente robados, desviados o interceptados, según el caso. Por otro lado, era característica del cine expresionista la predilección por los temas ocultistas y la magia ya que estos temas se prestaban especialmente para el despliegue ilusionista que posibilitaban las técnicas cinematográficas. Esto explica la cantidad de versiones fílmicas sobre la vida de este personaje que se produjeron en un lapso de apenas treinta años.

Revista Iberoamericana, Vol. LXXVII, Núms. 236-237, Julio-Diciembre 2011, 1051-1060 ISSN 0034-9631 (Impreso) 
Desde el prólogo el poeta propone explícitamente el pacto de lectura:

Suponga el lector que no ha comprado este libro en una librería, sino que ha comprado un billete para entrar al cinematógrafo.

Así, pues, lector, no vienes saliendo de una librería, sino que vas entrando al teatro. [...] se corren las cortinas [...] aparece el subtítulo general explicativo del argumento y lo más breve posible. (188)

Efectivamente, después de los dos puntos, la página, convertida en pantalla de proyección, exhibe una síntesis del argumento. La aclaración autoral “lo más breve posible” no alude, por cierto, a una convención literaria sino fílmica. Por consiguiente, desde un principio se nos propone una incorporación de las técnicas del cine a la escritura que dará como resultado la modificación radical de las convenciones representativas de esta última y el surgimiento de un género nuevo: la novela-film. La hibridez de este nuevo género, evidenciada en su nombre mismo, determina que de allí en más el narrador relatará por un lado la historia de Cagliostro y, al mismo tiempo, la representación fílmica de esta historia. Es decir que el pacto de lectura propuesto por Huidobro reclama un lector/ espectador que ocupará alternativamente los dos lugares. Así, el comienzo mismo de la novela es eminentemente literario. Se destacan aliteraciones, juegos de palabras y metáforas, procedimientos todos imposibles de trasladar a la representación fílmica:

Una tempestad del siglo xvIII retumbaba aquella tarde de otoño sobre la Alsacia adormecida, sobre la dulce Alsacia rubia a causa de sus hojas y de sus hijas. [...] De cuando en cuando el lanzazo de un relámpago magistral vaciaba sobre la angustia de nuestro panorama la sangre tibia de una nube herida. (189)

Pero inmediatamente volvemos a tener la pantalla ante nosotros. Allí, el espacio representado se ordena en relación con la presencia física, real, del lector/espectador: "a la derecha del lector, la lluvia y la fragua activa de la tempestad; a la izquierda, una selva y colinas” (189). De manera que la aceptación del pacto implica que debemos leer la novela sin perder de vista que estamos sentados en una sala de cine. La siguiente frase condensa claramente el esfuerzo de síntesis representacional que Huidobro se propone:

Toda esta página que acabamos de escribir está atravesada por un camino lleno de fango, de charcas de agua y de leyendas. Una carroza misteriosa [...] avanza sobre el lector al galope compacto de sus caballos, cuyos enormes cascos de hierro hacen temblar toda mi novela (189, énfasis mío).

De acuerdo con esto, la dimensión espacial de la escritura se muestra en todo su espesor. La novela entonces deja de ser únicamente el espacio simbólico de los signos

Revista Iberoamericana, Vol. LXXVII, Núms. 236-237, Julio-Diciembre 2011, 1051-1060 
para constituir el lugar concreto donde verdaderamente ocurre lo que se narra. La página es la pantalla, y viceversa. La lectura transcurre al mismo tiempo que la contemplación, y los acontecimientos tienen lugar efectivamente ante nuestros ojos. El correlato de esta doble recepción es la configuración de un espacio singular donde el lector es materialmente afectado por lo que ocurre en su presencia:

La carroza llega delante de nosotros, muy cerca, a algunos metros de nuestros ojos. La lluvia se encarniza intencionalmente sobre el mayoral. Mi feo lector o mi hermosa lectora deben retroceder algunos metros para no ser salpicados por las ruedas de este misterio que pasa (189). ${ }^{5}$

De este modo, el narrador de la novela será predominantemente un relator o presentador que se limitará a describir en simultáneo lo que se ve en la pantalla, reubicándonos una y otra vez en nuestro papel de espectadores.

La doble articulación del narrador/presentador produce una permanente tensión entre la posición clásica de un narrador en tercera, y la conjetura de quien contempla la proyección al mismo tiempo que nosotros. Cuando el mago reúne secretamente a sus amigos para trasmitirles los secretos de la Ciencia Oculta, afuera hay un gran movimiento de gente:

Alguien ha colocado allí a esos dos músicos, alguien ha provocado artificiosamente esa aglomeración popular. ¿Con qué objeto? Tal vez para que nadie se aperciba de ciertos personajes que entran en una casa vecina. Algunos de esos personajes nos son conocidos. Yo, por mi parte, he distinguido entre ellos al príncipe de Soubisse y al conde de Sablons. (220)

Al mismo tiempo, el doble anclaje estético del texto se pone en evidencia toda vez que el narrador, cuando hace las veces de "presentador", nunca apela a los "espectadores" sino a los lectores. Lejos de constituir una incongruencia, creo que esta aparente contradicción alude precisamente al doble papel que asumen tanto el enunciador como el lector implícito. ${ }^{6}$

Cuando Cagliostro desciende de la carroza, esa misma voz nos interpela: “¿Habéis visto sus ojos? Sus ojos fosforescentes como los arroyos que corren sobre las minas

5 El pacto de lectura que nos propone Huidobro en esta novela puede entenderse como la culminación de los postulados creacionistas que el poeta enuncia en su poema-manifiesto “Arte Poética”: "Por qué cantáis la rosa, ¡oh poetas! / Hacedla florecer en el poema”. Este poema forma parte de El espejo de agua publicado en Buenos Aires en 1916.

6 Fernando Sánchez Martín, por ejemplo, se sorprende de que “Huidobro, tan preocupado por cada detalle, escriba 'mi feo lector' y no 'mi feo espectador'”' (123).

Revista Iberoamericana, Vol. LXXVII, Núms. 236-237, Julio-Diciembre 2011, 1051-1060

\begin{tabular}{l} 
ISSN 2154-4794 (Electrónico) \\
\hline ISSN 0034-9631 (Impreso)
\end{tabular}


de mercurio [...]. Miradlos bien, porque esos ojos son el centro de mi historia y han atravesado todo el siglo XviII como un riel electrizado" (189). ${ }^{7}$

Sin embargo, no solo la mirada del lector /espectador resulta decisiva para que la doble representación de la historia tenga lugar. De hecho, a nivel argumental, el mayor instrumento de poder del mago radica en la fuerza de su mirada. Cagliostro abre puertas sin tocarlas e hipnotiza a otros personajes, fundamentalmente a su esposa, a quienes utiliza como medium para obtener la información que necesita. ${ }^{8}$ Pero además, el narrador alude insistentemente a los ojos de todos los personajes y a las miradas que estos se prodigan, de modo tal que la intriga avanza en virtud de las diversas significaciones encarnadas en estas:

En la sala de espera algunos enfermos aguardan aun su turno, con los ojos brillantes de buen presagio, esos ojos abiertos al imposible que no se habían visto en el mundo desde los tiempos del Mesías. (193)

En ese instante la puerta se abre y Cagliostro aparece con [...] un gesto diabólico en los ojos.

Los médicos se miran, sorprendidos. El doctor Ostertag clava en el intruso una mirada audaz sosteniendo la mirada de Cagliostro. (207)

La historia se entreteje con los hilos de las miradas. La apuesta estética se juega abiertamente al plano de lo escópico, remedando la especial relevancia de los ojos en los modos de construcción de sentido del cine expresionista. Así, es paradigmática la escena en que aparece por primera vez el personaje de Lorenza. En primer lugar, se nos ofrece una indicación escénica:

Es la alcoba de Lorenza, la esposa del taumaturgo. Lorenza lee sentada en un sillón en medio de la alcoba. ${ }^{9}$

Al sentir que Cagliostro se acerca, aun antes que él haya abierto la puerta y corrido las cortinas, Lorenza se levanta con el rostro convulso y los ojos llenos de espanto, huye como queriendo esconderse en el rincón opuesto [...]. (195)

7 Esta comparación, de cuño típicamente vanguardista, no solo rinde culto a las "maravillas" de la Modernidad sino que además pone en práctica uno de los principios constructivos de la imagen creacionista: la conjunción de lo abstracto y lo concreto, de lo material y lo inmaterial, que Huidobro propone en su manifiesto “El creacionismo” publicado en Manifestes (1925).

8 De acuerdo con Eva Valcárcel, "este uso de la mirada en el texto posibilita la lectura simbólica del verbo mirar como un acto de voluntad ejercido desde un sujeto agente sobre un sujeto pasivo" (Valcárcel, "Vicente Huidobro" 504).

9 Otro ejemplo de indicación escénica: "Momento angustioso. Aquí la capa cae lentamente de sus hombros” (190).

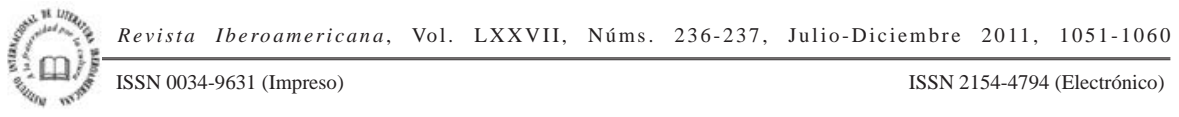


La descripción del gesto y de los ojos de la mujer “relatan” los movimientos del otro personaje, que hasta este momento ha permanecido fuera de campo. Inmediatamente la puerta se abre, se separan las cortinas y Cagliostro aparece. Sin embargo, la acción se juega otra vez fuera de campo ya que acto seguido se nos propone un primer plano del rostro de la esposa: "Lorenza, por el terror que va aumentando en sus ojos abiertos, indica el aproximarse del mago, como si cada uno de sus pasos se posara en sus pupilas” (195).

En varios momentos del texto la escena se recorta para mostrar en primer plano el punto de concentración donde confluyen las miradas de los personajes y la del lector. Cuando el protagonista, ante los requerimientos de la marquesa Eliane, accede a brindar a sus amigos una muestra de sus poderes, ofrece una representación de la muerte del marido de esta dama, que efectivamente murió unos años atrás en un duelo. Esta visión tiene lugar dentro de una pecera llena de agua "en la cual se ven aparecer dos hombres que se baten en un duelo a espada” (198). El particular interés de esta escena radica en que la magia ejecutada por el protagonista coincide con las posibilidades de representación que ofrecen las técnicas del cine. Sin duda, semejante escena es pasible de volverse real gracias al montaje y la sobreimpresión. Cuando el duelo se resuelve con la muerte del marqués, el agrandamiento progresivo de la imagen sugiere el paulatino acercamiento de la cámara para obtener un plano detalle: "al interior de la pecera la cabeza del herido se agranda, se vuelve enorme, enormemente enorme, desborda de la pecera y ocupa toda la escena. La cabeza sola, con una herida en la frente, abierta, chorreando sangre, la cabeza es como un muro ante nuestros ojos" (198).

El mismo procedimiento se vuelve a utilizar en otras dos escenas "mágicas" de la novela: cuando los reyes, en la corte, contemplan horrorizados sus futuras cabezas guillotinadas en la superficie de un gran espejo, ${ }^{10} \mathrm{y}$ cuando Cagliostro intercepta el vuelo de una paloma mensajera para leer el mensaje que ésta lleva. El mago coloca la carta sobre la frente de Lorenza. Entonces:

La cabeza de Lorenza se agranda ante nuestros ojos [...]. Su rostro se torna fluídico y la carta toma el sitio de su frente de tal modo que se pueden leer por transparencia las frases siguientes [...].

Leída la carta, gracias a la doble vista de Lorenza, el rostro y la cabeza de la médium vuelven a su estado normal. Se reducen a la quinta parte. (204)

\footnotetext{
${ }^{10}$ Esta visión constituye una anticipación o flash-forward que muestra la caída de la Monarquía y el advenimiento de la República Francesa. Del mismo modo, un flashback permite contemplar las pruebas de iniciación que Cagliostro debió atravesar en Egipto muchos años atrás, para ser aceptado en la Logia de los Rosacruces. Edmundo Paz Soldán propone entender estos episodios "como parte del deslumbramiento que los trucos cinematográficos, a través de la edición y el montaje, suscitaron en las vanguardias y en el público en general” (160). Revista Iberoamericana, Vol. LXXVII, Núms. 236-237, Julio-Diciembre 2011, 1051-1060
ISSN 2154-4794 (Electrónico)
} 
A la inversa, varias escenas se resuelven con el acercamiento o alejamiento del personaje hasta pederse de vista. Para esto, las descripciones suponen evidentemente una cámara fija y un plano-secuencia con profundidad de campo:

Cagliostro aparece de pronto en el sendero hacia la carroza. A medida que se acerca parece que se agranda de un modo increíble. Llega, sube a la carroza y parte al galope. Al fondo del camino, cuando está muy lejos, no se ve sino el pequeño tragaluz detrás, en forma de almendra, como un ojo sonriente entre la tierra y el cielo. Después una nube especial desciende hasta el suelo para ocultarla a la curiosidad humana. (192-93)

Aquí reconocemos también, en el paulatino oscurecimiento de la imagen, el fundido a negro que solía marcar el pasaje de un plano a otro.

Todas las escenas se separan entre sí por un espacio en blanco con un mínimo circulito en el medio que remeda la operación de montaje. ${ }^{11}$ Algunas veces, una breve leyenda en cursiva, centrada y separada del relato propiamente dicho indica, a la manera de los carteles del cine mudo, las circunstancias espacio-temporales de la acción: "En un barrio alejado del centro de París..., una casa solitaria” (213); o "En el palacio del príncipe Rolland” (216); o "Muy lejos de allí...” (217). Pero cuando dos escenas transcurren al mismo tiempo, se recurre al montaje alterno para indicar la simultaneidad. Esto sucede, por ejemplo, cuando Lorenza, en estado de hipnosis, narra al mago lo que "ve" ocurrir en casa del prefecto de policía. En un momento dado el relato de la medium se interrumpe y la cámara se traslada de la alcoba de Lorenza a la casa del Prefecto, de manera que nos es dado ver lo que efectivamente está sucediendo allí, para volver finalmente a la escena inicial en la que "la esposa del mago continúa su relato, sentada en un gran sillón, la cabeza echada hacia atrás, inmóvil, los ojos hipnotizados fijos en el techo” (203).

Por todo lo dicho, resulta evidente que la operación transpositiva que emprende Huidobro en esta novela no se agota ni se detiene en la ekfrasis. ${ }^{12}$ Es decir, no se trata solamente de leer la página como se mira una pantalla, sino que la escritura misma de esta novela se organiza de acuerdo con las técnicas del cine. Sin embargo, el gesto huidobriano va todavía más allá desde el momento en que los procedimientos constructivos tanto literarios como cinematográficos son reiteradamente objeto de un juego paródico que desenmascara los clichés y los convencionalismos estéticos. Cuando Cagliostro desciende al antro donde están reunidos los Rosacruces, “a sus ojos aparece un gran

${ }^{11}$ Sánchez Martín sostiene acertadamente que "cada párrafo constituye [...] el equivalente literario del plano fílmico" (123).

12 Se entiende por ekfrasis la descripción, en poesía o prosa, de un objeto artístico. Esta figura tiene como intención la captura de lo visual con palabras. La figura de la ekfrasis alcanzó su auge durante el período victoriano, en donde los poemas tenían por tema privilegiado diferentes aspectos visuales de la naturaleza como, por ejemplo, los paisajes (ver Belén Gache, La poética visual”).

Revista Iberoamericana, Vol. LXXVII, Núms. 236-237, Julio-Diciembre 2011, 1051-1060 ISSN 0034-9631 (Impreso) 
salón de estilo Edad Media para cinema” (190). De este modo, mediante un guiño a los espectadores de cine supuestamente habituados a determinadas escenografías y decorados, Huidobro establece una distancia crítica respecto de las convenciones del nuevo arte, pero por otro, precisamente mediante la alusión al cliché, logra evitar la descripción de la sala, lo cual le permite una vez más poner en práctica los postulados creacionistas. ${ }^{13}$ En este mismo sentido, más adelante el narrador vuelve a eludir otra descripción cuando se refiere a "uno de los magníficos salones del príncipe [Rolland], un gran salón de estilo (del estilo que más le guste al lector, a condición de que sea anterior a Luis XVI)" (216). Del mismo modo, ante la primera aparición de Lorenza, el narrador dice: "Lector, piensa en la mujer más hermosa que has visto en tu vida y aplica a Lorenza su hermosura. Así me evitarás y te evitarás una larga descripción” (195). O "Lector, coge una novela, lee en ella la descripción de cualquiera noche en la cual va a pasar un acontecimiento grave. Y luego continúa esta página” (235).

Por cierto, en todos los casos se requiere la colaboración y la complicidad de un lector sofisticado que posea las herramientas y recursos necesarios para asumir el desafío que el texto le propone, y que además se sienta dispuesto a seguir el juego. El procedimiento paródico al que echa mano Huidobro instaura una tensión entre la novedad cuestionadora y el reconocimiento de lo habitual, puesto que " [... el lector debe recrear situaciones y personajes por medio de imágenes importadas de otras experiencias visuales o textuales” (Sierra 44). Su actividad no consistirá entonces en un mero reconocimiento, característico del modo de lectura tradicional. Por el contrario, la lectura promovida por Huidobro consistirá en poner en marcha -a través del humor, la distancia crítica, la desautomatización, la desarticulación del cliché- una reapropiación crítica de lo conocido. El narrador ironiza, por ejemplo, sobre la tipificación de los personajes tradicionales: "La carroza de la marquesa espera a la puerta con el paciente cochero dormido sobre su asiento, siguiendo la vieja tradición de todos los cocheros poseídos por su papel” (205); "el príncipe [desesperadamente enamorado de la Marquesa] era en ese momento un príncipe encantado, encantado por los encantos de la encantadora" (218). En otro momento bromea sobre la correspondencia ya convencionalizada en el cine mudo entre los rasgos físicos de los personajes y sus atributos psíquicos, mediante la siguiente interpelación al lector: "(Ruego a los que estudian la Fisiognomía, que pongan atención en la cabeza del profesor Lavater, inventor de la ciencia de conocer el carácter por los rasgos del rostro)” (216). ${ }^{14}$

${ }^{13}$ Recordemos que Huidobro recomienda "nada de anecdótico ni descriptivo" en su ya mencionado manifiesto "El creacionismo". Sin embargo, la evitación de la descripción no solo responde a los postulados de la estética creacionista. También es necesario ver aquí una transposición del tempo del cine, más ágil y dinámico, a la novela.

${ }^{14}$ Sostiene De Costa que "[e]n los primeros tiempos del cine [...] se daba una suerte de fisiognomía convencional mediante la cual se atribuía a los rasgos físicos de los actores un carácter revelador de las cualidades mentales del personaje: los ojos astutos del villano, los ojos fulgurantes del amante” (72).

Revista Iberoamericana, Vol. LXXVII, Núms. 236-237, Julio-Diciembre 2011, 1051-1060

ISSN 2154-4794 (Electrónico)
ISSN 0034-9631 (Impreso)


Pero también los clichés lingüísticos, como ciertas comparaciones estereotipadas, son objeto de parodia: "La paloma parte como una flecha, es decir, partiría como una flecha, si esta comparación no fuera demasiado usada” (203), o "El cochero se ve magnífico en su actitud de detener los caballos espantados. Parece un monarca sobre el carro del Estado, al borde del abismo de la Revolución, etc.” (189). De manera que a la transposición artística, al cuestionamiento de los límites genéricos, ${ }^{15}$ se suma un trabajo con las convenciones estéticas que configura un nivel metanarrativo donde la novela re-flexiona sobre su propio hacerse. La renovación de la textualidad se lleva a cabo no solo mediante la incorporación de los avances tecnológicos a la escritura misma, lo que implica ya de por sí una radical modificación. ${ }^{16}$ El juego paródico con las convenciones y los procedimientos narrativos instaura en la novela un nivel metaliterario en el cual se desarticula meticulosamente toda ilusión de realidad. Si el ideal de la estética creacionista consistía en hacer florecer la rosa en el poema, si la imagen insólita significaba la creación de un nuevo objeto que venía a poblar el mundo en un plano absoluto de igualdad respecto del orden material, ahora mediante la parodia el poeta creacionista muestra sus trucos, abre los entretelones de su arte y exhibe el artificio que sostiene toda su creación. Por lo tanto, el Creacionismo resulta ser puro Ilusionismo, la pretendida creación no es más que una ilusión. Si al final de la novela, Cagliostro abomina de su saber y decide prender fuego a sus escritos, cancelando de este modo toda posibilidad de conservar su ciencia, también el poeta a su manera "prende fuego” al teatro de sus sortilegios, al dejar mirar la escena por detrás. ${ }^{17}$ En consecuencia, el mayor acto de prestidigitación no intentará hacer creer la realidad de lo imaginario ni simular una presencia donde solo hay ausencia. Por el contrario, el gran golpe de

15 "El desafío [...] de escribir una novela cinematográfica rompía desde ya con una concepción sostenida en el convencimiento de la autonomía e invariabilidad estructural del género”, sostiene Fernando Burgos (165).

16 "La transformación de lo artístico en la vanguardia comienza en la percepción de que es el medio lo primero a ser transformado" sostiene Fernando Burgos (168). Este autor explica la inicial indiferencia hacia la novela de Huidobro en el hecho de que la crítica todavía fijara su atención en el acontecimiento, en la historia narrada, y no en los procedimientos renovadores de la escritura (166).

${ }^{17}$ María Gracia Núñez Artola sugiere una comparación entre el final de la novela de Huidobro y el de otra novela sobre el mismo personaje, José Bálsamo, Conde de Cagliostro, escrita por José Velásquez y Sánchez en 1871, en la que se narra el juicio que recae sobre Giuseppe Bálsamo, acusado de ejercicio ilegal de la medicina y de falsificación y condenado a cumplir cadena perpetua en el Castel Sant' Angelo (Núñez Artola 14). Huidobro propone en cambio un final abierto y ambiguo, en el cual "el gran mago se pierde a los ojos del mundo detrás de esa nube misteriosa" (240), (fundido a negro) reinstaurando el misterio. Las preguntas del último cartel (“¿Qué pasó después? ¿A dónde fue a refugiarse? ¿Pudo vencer a la muerte? ¿Vive aun con los suyos en alguna parte?” [240]) sugieren la posible continuación de la película en un nuevo episodio, apelando una vez más a las convenciones del cine. Pero además, el incendio de los papeles como final de la historia admite una lectura metapoética, habitualmente presente en la escritura de Huidobro.

Revista Iberoamericana, Vol. LXXVII, Núms. 236-237, Julio-Diciembre 2011, 1051-1060
ISSN 2154-4794 (Electrónico) 
magia, el as bajo la manga del poeta-mago será mostrar lo imaginario de la realidad, lo ilusorio de la presencia. Así, el verdadero ilusionista será, en definitiva, el gran artífice de la des-ilusión.

\section{BiBLIOGRAFÍA}

Burgos, Fernando. "La vanguardia hispanoamericana y la transformación narrativa”. Nuevo texto crítico II/3 (1989): 157-69.

Costa, Renéde. "El cubismo literario y la novela fílmica: Cagliostro de Vicente Huidobro”. Revista de crítica literaria latinoamericana III/6 (1977): 67-79.

Domenella, Ana Rosa. "Vicente Huidobro 1934: tres dispares novelas". Cuadernos americanos IV/58 (1996): 163-74.

Gache, Belén. "La poética visual: en las fronteras entre leer y ver”. Páginas de guarda, revista de lenguaje, edición y cultura escrita 2 (2006): 137-50.

Huidobro, Vicente. Cagliostro. Obras completas de Vicente Huidobro. Hugo Montes, ed. Vol. II. Sangiago de Chile: Andrés Bello, 1976. 185-240.

“El creacionismo”. Manifestes. París: Review Mondiale: 1925.

Iglesias Pérez, María. "Vicente Huidobro: Cagliostro, subversión creacionista". Cartaphilus 2 (2007): 78-82.

Leferre, Robin. “Ambigüedades y estrategias en Cagliostro, ¿novela-film?”. Foro Hispánico: Revista Hispánica de los Países Bajos 14 (1999): 121-33.

Núñez Artola, María Gracia. “Aspectos formales en la novela de ‘vanguardia’: Caligostro de Vicente Huidobro”. Espéculo. Revista de estudios literarios 25 (2003). <www. ucm.es/info/especulo/numero25/cagliost.html-92k>. 9 marzo 2011.

Paz Soldán, Edmundo. "Vanguardia e imaginario cinemático: Vicente Huidobro y la novela-film”. Revista Iberoamericana LXVIII/198 (2002): 153-63.

Ruiz Stull, Miguel. "Prefacio, la lógica de Huidobro”. MLN 122/2 (2007): 315-41.

Saldes Báez, Sergio. "La novela-film. Algunas consideraciones acerca de Cagliostro de Vicente Huidobro”. Literatura y Lingüística 2 (1988): 69-80.

Sánchez Martín, Fernando. "La narrativa de vanguardia en Cagliostro. Una poética cinematográfica”. Quaderni Iberoamericani 92 (2002): 109-34.

Sierra, Marta. "Fragmento, recolección y nostalgia: la figura del artista en la literatura de vanguardia hispanoamericana”. Confluencia. Revista Hispánica de Cultura y Literatura XVIII/2 (2003): 42-52.

Valcárcel, Eva. "Vicente Huidobro y los límites de la novela. Fragmentos para una teoría de la novela de vanguardia”. Anales de Literatura Hispanoamericana II/ 26 (1997): 497-507.

"El engendramiento del objeto: vanguardia pictórica y prosa literaria hispanoamericana”. América Latina: literatura e historia entre dos finales de siglo. Sonia Mattalía y Joan del Alcázar, comps. Valencia: CEPS, 2000. 249-66.

Revista Iberoamericana, Vol. LXXVII, Núms. 236-237, Julio-Diciembre 2011, 1051-1060 